\title{
A ESCOLA COMO LOCUS DO DEBATE DAS QUESTÕES DE GÊNERO: UMA ANÁLISE DA CONSTITUCIONALIDADE DO PROJETO DE LEI "ESCOLA SEM PARTIDO"
}

\author{
Fabrício Veiga Costa ${ }^{1}$ \\ Mariel Rodrigues Pelet ${ }^{2}$
}

\section{RESUMO}

O debate crítico das questões de gênero no âmbito escolar legitima o exercício da cidadania, garante a igualdade, permite a inclusão, reprime a violência simbólica, além de retirar da invisibilidade pessoas que destoam dos padrões heterossexuais da moralidade vigente. $\mathrm{O}$ Projeto de Lei "Escola Sem Partido" propõe a neutralidade cientifica do docente ao impedir o debate político das questões de gênero na escola. Tal projeto de lei é inconstitucional por violar a liberdade de cátedra, o direito fundamental à liberdade sexual e estimular o preconceito, segregação e marginalidade de pessoas que manifestam sua orientação de gênero na sociedade contemporânea.

Palavras-Chave: Direito Fundamental à Educação; Gênero; Sexualidade; Projeto de Lei Escola Sem Partido; Constitucionalidade.

\section{THE SCHOOL AS LOCUS OF THE DISCUSSION OF GENDER ISSUES: AN ANALYSIS OF THE CONSTITUTIONALITY OF THE LAW PROJECT "SCHOOL WITHOUT PARTY"}

\begin{abstract}
Critical debate on gender issues at the school level legitimizes the exercise of citizenship, guarantees equality, allows inclusion, represses symbolic violence, and removes from invisibility people who disregard the heterosexual standards of current morality. The "NoParty School" Bill proposes the scientific neutrality of teachers by preventing political debate on gender issues in school. Such a bill is unconstitutional for violating academic freedom, the fundamental right to sexual freedom, and to stimulate the prejudice, segregation and marginalization of people who manifest their gender orientation in contemporary society.
\end{abstract}

Key Words: Fundamental Right to Education; Genre; Sexuality; Law Project No Party School; Constitutionality.

\footnotetext{
${ }^{1}$ Pós-Doutorado em Educação pela UFMG (2015). Doutorado em Direito Processual (2012) pela Pucminas. Mestrado em Direito Processual (2006) pela Pucminas. Especialista em Direito Processual (2003), Direito de Família (2009) e Direito Educacional (2013) pela Pucminas. Bacharel em Direito pela Universidade Federal de Uberlândia (2001). Professor do Programa de Pós-graduação stricto sensu em Proteção dos Direitos Fundamentais da Universidade de Itaúna -MG-.

${ }^{2}$ Mestranda em Proteção dos Direitos Fundamentais pela Universidade de Itaúna -MG-.
} 


\section{INTRODUÇÃO}

O objetivo geral do presente artigo científico é investigar a legitimidade democrática da escola, no Brasil, debater questões de gênero, procurando-se compreender e demonstrar que tal debate é uma forma de garantir a inclusão, superar desigualdades, reprimir violências e ressignificar preconceitos sofridos por pessoas que fogem ao padrão sexual imposto pela moral social vigente.

Especificamente pretende-se analisar o conteúdo do projeto de lei intitulado "Escola Sem Partido", compreender seus fundamentos e evidenciar que se trata de proposta legislativa que proíbe o debate das questões de gênero no âmbito escolar.

Nesse contexto, a escola passa a ser vista como um espaço privado de extensão dos valores morais e cristãos, onde o debate da sexualidade e de gênero não é permitido. $O$ professor deverá demonstrar neutralidade cientifica na abordagem de temas como política e sexualidade, por considerar a escola um local de reprodução dos valores familiares.

A escolha do presente tema justifica-se em razão de sua relevância prática e teórica, considerando-se que o pluralismo e a diversidade social são aspectos levados para a escola e que marcam a sociedade atual. A sala de aula deve ser vista como um espaço de heterogeneidade de concepções e vivências de mundo. O debate dessa pluralidade multifacetária é fundamental para o reconhecimento e o respeito do outro no âmbito da dignidade humana.

A pergunta problema que norteará todo debate cientifico proposto é a seguinte: a sala de aula é o espaço que legitima democraticamente o debate crítico das questões de gênero que marcam a sociedade brasileira contemporânea? O projeto de lei denominado "Escola Sem Partido" pode ser considerado constitucional, ao proibir a abordagem e a discussão das questões de gênero no ambiente escolar?

O estudo da temática em tela passa inicialmente pelo entendimento da educação como um direito fundamental corolário do exercício da cidadania no Estado Democrático de Direito. A escola é o espaço de debate e de formação crítica do cidadão; é o local onde o pluralismo e a diversidade se encontram e dialogam. A mesma escola que inclui e assegura a igualdade, poderá excluir, marginalizar e perpetuar a desigualdade entre as pessoas.

O debate crítico do papel da escola nas sociedades democráticas é fundamental ao entendimento do tema proposto. É na instituição escolar que as pessoas têm a oportunidade de 
desmitificar gênero e sexualidade, repensar o binarismo, abandonar a categorização das pessoas em razão da orientação de gênero e compreender que a patologização é uma metodologia de exclusão e invisibilidade das pessoas.

A compreensão da constitucionalidade do projeto de lei "Escola Sem Partido" passa pela análise da liberdade de cátedra, visando entender se a proposta da neutralidade cientifica retira ou não a liberdade do professor pensar e refletir criticamente no espaço escolar. A análise do respectivo projeto é fundamental para averiguar se pode ser considerado um meio de legitimar a censura, ao proibir do debate de política e questões de gênero no ambiente da escola.

O direito fundamental à liberdade sexual e de gênero é outro fundamento utilizado como parâmetro ao estudo da constitucionalidade do projeto de lei "Escola Sem Partido". Proibir o debate do gênero institucionalmente na escola é um meio de reprimir o exercício do direito de liberdade sexual, além de explicitar a exclusão das pessoas que manifestam sua sexualidade fora dos padrões impostos pela heterossexualidade vigorante.

Quanto à metodologia, foi desenvolvida a pesquisa bibliográfica nos autores e estudiosos que debatem a temática proposta, construindo-se análises temáticas, teóricas e interpretativas para viabilizar o debate crítico-epistemológico do objeto de investigação. A realização da pesquisa documental em textos de lei, constituição brasileira de 1988 e projetos de lei foi essencial ao entendimento sistemático da dimensão do estudo proposto. A delimitação do tema se deu a partir do método dedutivo, partindo-se do estudo macroanalítico do direito fundamental à educação, especificando a análise na constitucionalidade do projeto de lei denominado "Escola Sem Partido", principalmente no que atine ao debate das questões de gênero no espaço escolar.

\section{DIREITO FUNDAMENTAL À EDUCAÇÃO E EXERCÍCIO DA CIDADANIA: A ESCOLA COMO LOCUS DO PLURALISMO, DIVERSIDADE, EXCLUSÃO E DESIGUALDADES}

A interpretação jurídica, constitucional, extensiva e sistemática do Direito Fundamental à Educação compreende o direito de ir, frequentar, estar e ser parte integrante do 
ambiente escolar. Trata-se de um direito público-subjetivo ${ }^{3}$, corolário da dignidade da pessoa humana. Além de a escola ser um espaço onde crianças e adolescentes buscam e encontram instrução formal, é sabido que se trata da oportunidade de os alunos conviverem com a diversidade e a pluralidade de concepções e visões de mundo.

Por se tratar de um Direito Social Fundamental, a Educação, segundo o artigo 205 da Constituição brasileira de 1988, busca o pleno "desenvolvimento da pessoa humana, seu preparo para o exercício da cidadania e sua qualificação para o trabalho". Trata-se de "um bem fundamental à vida digna, existindo como atributo intrínseco da própria democracia, desta fazendo parte indissociável” (SILVA, 2015).

Segundo Esméria de Lourdes Saveli e Maria Odete Vieira Tenreiro “o Brasil conta, atualmente, com uma constituição guiada pelo princípio da cidadania, acenando para uma perspectiva mais universalizante do direito à educação" (SAVELI; TENREIRO, 2015).

É importante esclarecer que "a educação representa tanto um mecanismo de desenvolvimento pessoal do indivíduo, como da própria sociedade em que ele se insere" (MONTEIRO, 2015).

"Enquanto fundamental ao desenvolvimento pleno do homem, a efetivação do direito à educação, como instrumento de transformação social, compreende a própria dignidade à pessoa humana como direito anterior à própria formação do Estado" (SILVA, 2015).

A Educação é um direito indisponível, por ser considerado essencial aos anseios e objetivos da sociedade. Não se trata de direito de espectro exclusivamente individual, uma vez que o seu exercício está diretamente atrelado à concretização dos fins e dos objetivos do Estado.

A indisponibilidade do Direito Fundamental à Educação é explicada a partir do interesse público na sua proteção jurídica e tutela específica. Tal indisponibilidade não decorre da natureza privada ou pública das relações jurídicas que lhes são subjacentes, mas da importância que elas têm para a sociedade (BRASIL, STF, RE $n^{\circ}$ 248.869). O interesse público de que se cogita é aquele relacionado à estabilidade das relações sociais. $\mathrm{O}$ direito individual indisponível é aquele que a sociedade, de forma direta ou por meio de seus representantes, reputa como essencial ao alcance dos seus anseios e objetivos.

\footnotetext{
3 “[...] o direito público subjetivo configura-se como um instrumento jurídico de controle da atuação do poder estatal, pois permite ao seu titular constranger judicialmente o Estado a executar o que deve. De fato, a partir do desenvolvimento deste conceito, passou-se a reconhecer situações jurídicas em que o Poder Público tem o dever de dar, fazer ou não fazer algo em benefício de um particular. Como todo direito cujo objeto é uma prestação de outrem, ele supõe um comportamento ativo ou omissivo por parte do devedor" (DUARTE, 2004, p. 113).
} 
A cidadania é um dos fundamentos da República Federativa do Brasil, expressamente previsto no artigo $1^{\circ}$, da Constituição brasileira de 1988. Ser cidadão é conferir aos indivíduos aptidão no que tange à efetiva possibilidade de exercício de seus Direitos Fundamentais.

Luiz Alberto David Araújo e Vidal Serrano Nunes Júnior (2004, p. 79), no que atine ao entendimento acerca do que é cidadania, assim se posicionam:

A expressão cidadania, aqui indicada como fundamento da República, parece não se resumir à posse de direitos políticos, mas, em acepção diversa, parece galgar significado mais abrangente, nucleado na ideia, expressa por Hannah Arendt, do direito a ter direitos. Segue-se, nesse passo, que a ideia de cidadania vem intimamente entrelaçada com a de dignidade da pessoa humana.

Em todo esse contexto jurídico-constitucional, verifica-se que a escola é um lócus de preparação dos indivíduos para o exercício da cidadania. Trata-se da oportunidade de ter acesso à instrução técnico-formal, além de conviver com realidades plurais e com a diversidade, característica prevalente e indispensável às sociedades democráticas. $\mathrm{O}$ direito de ir à escola materializa a oportunidade de construção da condição de cidadão no Estado Democrático de Direito.

A erradicação de qualquer forma de discriminação decorrente da origem, raça, sexo, cor e idade constitui objetivo fundamental da República Federativa do Brasil, expressamente previsto no disposto no artigo $3^{\circ}$ da Constituição brasileira de 1988. Assim, a escola é o espaço onde crianças e adolescentes têm de conviver com a diversidade e o pluralismo social. É a oportunidade que possuem de construir valores, de conviver com o novo, de vivenciar experiências distintas daquelas típicas de seu ambiente familiar.

É na escola que a criança tem a oportunidade de experimentar situações diversas além daquelas típicas do seu núcleo familiar. É o nicho onde se constrói e desconstrói crenças e valores, revisita conceitos, aprende a conviver com o novo, reconhece o diferente, interioriza novas vivências, inicia a construção da sociedade democrática, prepara as pessoas para o exercício da cidadania.

No momento em que o legislador constituinte elencou a cidadania como um dos fundamentos da República Federativa do Brasil, estabelecendo como um dos objetivos fundamentais "a promoção do bem de todos, sem preconceito de origem, raça, sexo, cor, idade ou quaisquer outras formas de discriminação" (artigo $3^{\circ}$, inciso IV da Constituição 
Federal de 1988), certamente pretendeu construir uma sociedade mais livre, justa, igual e solidária a partir da escola.

Desde sua concepção, a escola sempre foi um espaço de segregação, distinções e desigualdades, pois "se incumbiu de separar os sujeitos - tornando aqueles que nela entravam distintos dos outros, os que a ela não tinham acesso". Na realidade, a escola "dividiu também, internamente, os que lá estavam, através de múltiplos mecanismos de classificação, ordenamento, hierarquização" (LOURO, 2014, p. 61).

Originariamente concebida para acolher as pessoas, a escola passou a ser vista como um local de categorização dos indivíduos, separando-os em brancos e negros; pobres e ricos; meninos e meninas; normais e deficientes; católicos e protestantes. A escola delimita espaços e dita padrões sobre "o que cada um pode (ou não pode) fazer, ela separa e institui. Informa o lugar dos pequenos e dos grandes, dos meninos e das meninas" (LOURO, 2014, p. 62).

A violência simbólica ${ }^{4}$, muitas vezes explicita, implícita ou velada, passa a ser uma realidade vivenciada no cotidiano da escola por aqueles alunos que não se enquadram nos padrões impostos pela ditadura escolar, que reproduz marginalidade e exclusão ${ }^{5}$. Buscando-se combater a violência no âmbito institucional, o governo federal lançou, no ano de 2004, o "Brasil Sem Homofobia" - Programa de Combate à Violência e à Discriminação contra GLTB e de Promoção da Cidadania Homossexual, cujas diretrizes educacionais propostas são as seguintes:

Elaborar diretrizes que orientem os Sistemas de Ensino na implementação de ações que comprovem o respeito ao cidadão e à não discriminação por orientação sexual; fomentar e apoiar curso de formação inicial e continuada de professores da área da sexualidade; formar equipes multidisciplinares para avaliação dos livros didáticos, de modo a eliminar aspectos discriminatórios por orientação sexual e a superação da homofobia; estimular a produção de materiais educativos (filmes, vídeos e publicações) sobre orientação sexual e superação da homofobia; apoiar e divulgar a produção de materiais específicos para a formação de professores; divulgar as informações cientificas sobre sexualidade humana; estimular a pesquisa e a difusão de conhecimentos que contribuam para o combate à violência e à discriminação de GLTB; criar subcomitê sobre Educação em Direitos Humanos no Ministério da Educação, com a participação do movimento de

\footnotetext{
4 "O fundamento da violência simbólica reside nas disposições modeladas pelas estruturas de dominação que a produzem” (BOURDIEU, 2007, p. 54).

5 "Mas o que se percebe é que a realidade educacional é excludente e seletiva, ainda que seja fruto desse processo histórico do patriarcado que demarcou os espaços de atuação do masculino e do feminino, como um espaço de construção do conhecimento cabe à escola subverter essa situação firmando-se a partir de um novo modelo de ação que priorize práticas transgressoras desses saberes que ainda legitimam o poder masculino e reproduzem falas preconceituosas" (OLIVEIRA, 2015, p. 264-265).
} 
homossexuais, para acompanhar e avaliar as diretrizes traçadas (BRASIL, 2004, p. 22 apud SEVERO, 2013, p. 31-32).

Tais proposições legislativas visam conscientizar e orientar a sociedade civil, instituições públicas e privadas, em todas as suas instâncias, para "somar esforços na luta contra a discriminação por orientação sexual” (SEVERO, 2013, p. 32).

A escola deve ser o espaço de amplo debate das questões de gênero e sexualidade, de modo a assegurar a inclusão e reprimir quaisquer condutas que marginalizam e excluem pessoas em razão das mais diversas manifestações de gênero. Assim, "no campo da educação, gênero pode ser abordado como temática e como conceito teórico, contribuindo para um educar para a valorização da diversidade" Dessa forma, "abre-se a possibilidade para trabalhar em sala de aula envolvendo diferentes campos, bem como o trabalho, sexualidade, política, educação, direitos, violência, saúde, revelando desigualdades a serem refletidas e, por fim, rompidas" (JARDIM; TUSSI, 2013, p. 186).

A instituição escolar é um local privilegiado de socialização e sociabilidade, onde se convive com discursos plurais, são construídas identidades, ressignificados conceitos, compreendido o outro no âmbito de suas escolhas e individualidades. Por isso, “é imprescindível a compreensão da análise de gênero na instituição escolar, visando a contribuição de comportamentos e práticas não-sexistas, aceitação da diversidade e tolerância do outro" (OLIVEIRA, 2015, p. 267).

Trazer para a escola o debate e a reflexão das questões de gênero é oportunizar aos alunos o rompimento com o processo histórico-patriarcal, além da superação do currículo escolar androcêntrico, racista, misógino e machista. Em contrapartida, obstaculizar que tais debates ocorram na instituição escolar é manter a tradição que prioriza uma educação binária, com predominância do homem sobre a mulher e invisibilidade de qualquer outra manifestação de gênero. Nesse contexto, "os estudos de gênero vêm, também, pressionar a escola a assumir sua posição como um espaço coletivo, sua condição de espaço público de embate dos problemas sociais de acolhimento aos vulneráveis e aos marginalizados e promoção do respeito à diversidade" (OLIVEIRA, 2015, p. 265).

A inclusão da temática do gênero e da sexualidade no currículo das escolas tem significativa importância na construção de identidades, estimulando o debate político de conteúdos de relevância social e resguardando a visibilidade dos excluídos em razão de sua orientação sexual. A partir dessas proposições, Rafael Adriano de Oliveira Severo afirma 
Discutir e problematizar as relações de gênero e sexualidade é uma das condições indispensáveis para a desconstrução e superação de estereótipos e de preconceito que têm gerado desigualdades entre meninos e meninas, mulheres e homens, homossexuais, bissexuais, travestis, transgêneros e heterossexuais, inclusive no âmbito das escolas (SEVERO, 2013, p. 74).

O debate de temas envolvendo gênero e sexualidade é fundamental na formação dos professores, haja vista serem profissionais que lidam cotidianamente com situações que envolvem tais questões, necessitando de conhecimentos específicos ao entendimento da temática em tela, de modo a atuar criticamente como agente nas intervenções significativas junto aos seus alunos. O despreparo do docente na abordagem de tais temas no âmbito institucional enseja o silencio e inviabiliza a construção de entendimento crítico hábil a desconstrução do preconceito, perpetuando concepções históricas de marginalidade das pessoas em razão de suas manifestações de gênero.

\section{DESMITIFICANDO O GÊNERO E A SEXUALIDADE: A SUPERAÇÃO DO BINARISMO E DA CATEGORIZAÇÃO DAS PESSOAS PELA ORIENTAÇÃO SEXUAL}

A identidade sexual é uma construção psicossocial de cada indivíduo no âmbito de sua subjetividade. A compreensão cientificamente crítica do tema é fundamental para evitar a reprodução de preconceitos e concepções que marginalizam as pessoas em razão de suas manifestações de gênero e sexualidade.

Diferenciar sexo biológico, identidade de gênero e orientação ou desejo sexual é essencial ao entendimento preliminar da temática. "O sexo biológico é determinado no nascimento e se refere às características genotípicas e fenotípicas do corpo" (TAQUETTE, 2015, p. 52). A categorização do macho e da fêmea se dá a partir da genitália, momento em que se define preliminarmente as questões da sexualidade humana e inicia a construção histórica do preconceito. Nascer do sexo masculino na sociedade ocidental é sinônimo de virilidade, força e racionalidade; ser do sexo feminino é contentar-se com a subserviência, dominação masculina, assumir-se frágil e se submeter à castração sexual.

A orientação sexual é um conceito que determina "por quem o indivíduo se sente atraído para manter relações sexuais, podendo ser alguém do sexo oposto, do mesmo sexo ou de ambos" (TAQUETTE, 2015, p. 52). O desejo sexual não é predeterminado 
genotipicamente, pois se trata de escolhas, vontades e decisões subjetivas tomadas por cada indivíduo de acordo com suas experiências e o contexto social ao qual se encontra inserido. A atração sexual entre pessoas não é algo perene, visto que ao longo da vida cada pessoa tem a oportunidade de se desenhar e redesenhar no âmbito de sua sexualidade, fazendo escolhas que venham trazer satisfação e bem-estar.

Em contrapartida, a identidade de gênero "não é dada pela natureza; é socialmente construída" (TAQUETTE, 2015, p. 52). "O gênero é conceito que foi introduzido na década de 1970 na tentativa de diferenciar o que é da natureza humana daquilo que é determinado pela cultura, pela organização social” (TAQUETTE, 2015, p. 52-53).

A construção da condição de homem e de mulher não é algo predeterminado por critérios biológico-evolucionistas. O "ser homem" e o "ser mulher" decorre de escolhas subjetivas que recebem influências do universo psicossocial onde o indivíduo se encontra inserido. "As singularidades de cada indivíduo, de acordo com suas interações com o mundo, suas expectativas e exigências culturais, desempenham também um papel relevante na construção da identidade sexual” (WEREBE, 1979, apud TAQUETTE, 2015, p. 51).

Compreender o gênero a partir de proposições clássicas é reconhecer que tal conceito "se refere à rede de crenças, traços de personalidade, atitudes, sentimentos, valores, condutas e atividades que diferenciam mulheres e homens" (PROCHAT, 2014, p. 32).

O masculino e o feminino são conceitos de significados plurivalentes, pois homens e mulheres são diferenciados por questões biológicas (genitália, espermatozoides e óvulos), por descrições sociológicas (comportamentos categorizados socialmente como de "machos" e "fêmeas") ou por papéis sociais assumidos no âmbito sexual (comportamento proativo do homem e a passividade da mulher).

O debate da sexualidade na sociedade ocidental relaciona-se diretamente com crenças, ideologias e imaginações utilizados para categorizar corpos humanos. Tais construções demarcam espaços de exercício de poder e dominação. É uma forma de subjugar aqueles que destoam do padrão heterossexualizante dominante e imposto socialmente.

A sedimentação do preconceito através do discurso de ódio ao "diferente" tornam pessoas humanas invisíveis, além de ignorar o pluralismo como condição básica para o amadurecimento do debate crítico das questões de gênero nas sociedades democráticas. "Se não fossem diferentes, se cada ser humano não diferisse de todos os que existiram, existem ou virão a existir, os homens não precisariam do discurso ou da ação para se fazerem entender. 
Com simples sinais e sons, poderiam comunicar suas necessidades imediatas e idênticas" (ARENDT, 2007, p. 188).

O debate das questões de gênero é um importante marco nas lutas sociais pela implementação de políticas públicas para dar visibilidade às diversas manifestações de gênero e sexualidade existentes na sociedade contemporânea, marcada pelo pluralismo e diversidade. Trata-se de "uma forma semântica de resistência à naturalização de desigualdades existentes naturalização essa que é produzida e reproduzida por diversas instituições sociais, dentre as quais figuram as organizações religiosas" (LOPES, 2016, p. 20).

O estudo do gênero objetiva assinalar o caráter cultural das distinções existentes sobre o sexo biológico. Os primeiros estudos voltaram seus esforços na investigação das principais modalidades de sexismo operantes na sociedade contemporânea. Nesse cenário, o gênero deve ser compreendido como um revestimento social e cultural da diferença sexual, tendo sido concebido originariamente como uma construção social de papéis e desigualdades ancoradas no sexo.

Em sua definição clássica, expressa "a dinâmica hierarquizada das relações de poder assentadas sobre a sexualidade" (LOPES, 2016, p. 23), considerando-se que o feminino se define pela submissão e o masculino pela dominação. Os estudos de gênero englobam uma pluralidade de elementos constitutivos, materializados "no conjunto de representações culturais, artísticas e simbólicas que expressam imagens naturalizadas do que é ser homem ou ser mulher" (LOPES, 2016, p. 30).

O feminino e o masculino são manifestações psicossociais e representações simbólicas, compartilhadas de forma dinâmica na sociedade atual, que variam conforme contextos histórico-culturais. O gênero deve ser visto como uma construção histórica marcada pela mutabilidade, pois seu elemento constitutivo funda-se nas diferenças percebidas nas relações sociais entre os sexos.

A heterossexualidade compulsória é o padrão vigente na dinâmica social-ocidental, reflexo de uma ética sexual que categoriza pessoas, impõe modos de vida, dita o modelo de sexualidade a ser adotado e reproduz violência (BUTLER, 2003). "O gênero surge da busca por uma nova teoria que conseguisse explicar as desigualdades estruturais entre homens e mulheres" (SOUZA, 2016, p. 154).

A divisão sexual, decorrente de concepções biológico-sociais, define os papeis exercidos por homens e mulheres; "os homens exercem o poder, a violência e a política. Já as 
mulheres devem estar do lado oposto, submissas, cuidadoras, na esfera privada" (SOUZA, 2016, p. 160). Essa desigualdade existente domestica a mulher, colocando-a em posição de submissão frente ao homem. A violência de gênero que atinge a mulher, transgêneros, homossexuais e lésbicas "pode ser física, sexual, patrimonial, moral e psicológica, no âmbito público ou privado" (SOUZA, 2016, p. 155).

“Os gêneros são os significados culturais assumidos pelo corpo sexuado" (BUTLER, 2015, p. 26). Trata-se de proposição concebida originariamente para compreender que "a distinção entre sexo e gênero atende a tese de que, por mais que o sexo pareça intratável em termos biológicos, o gênero é culturalmente construído" (BUTLER, 2015, p. 25-26).

A história da humanidade foi construída a partir do modelo binário-cartesiano, ao preconizar que "o gênero se definia a partir do sexo concebido biologicamente, marca expressivamente pautada pelas ciências biológicas - de perspectiva positivista" (SEVERO, 2013, p. 61). Romper com o binarismo é superar o modelo taxonômico que classifica/categoriza pessoas humanas a partir da genitália, definindo o homem como o sujeito que tem pênis e a mulher a pessoa que possui vagina.

"Para as ciências sociais e humanas, o conceito de gênero refere-se à construção social em torno do sexo anatômico" (SEVERO, 2013, p. 62). A distinção da dimensão biológica e social da sexualidade é essencial ao entendimento de que a maneira de ser homem e de ser mulher é algo produzido culturalmente. "As várias formas de fazer-se mulher ou homem são construídas socialmente, são produtos da realidade social e não são naturalmente determinados pelas diferenças inscritas nos corpos, assim como o modo de viver desejos e prazeres corporais" (SEVERO, 2013, p. 62).

A concepção sobre o que é gênero no presente artigo cientifico refere-se a uma construção social sobre o que é o feminino e o masculino, distinta da identidade sexual e orgânica com a qual as pessoas nascem.

A “Teoria Queer" propõe o entendimento crítico da sexualidade no âmbito da subjetividade dos indivíduos, buscando-se superar jargões, conceitos e preconceitos socialmente instituídos. O termo queer foi inicialmente "direcionado a pessoas que, de alguma maneira, escapavam às expectativas de gênero e sexualidade socialmente construídas. Dessa forma, queers eram os gays afeminados, as lésbicas masculinizadas, as travestis, as pessoas andróginas e todos os sujeitos que não estavam de acordo com os padrões heterossexuais e cisgêneros" (ALKMIN, 2016, p. 230). 
Tal teoria propõe a superação das classificações e categorizações marginalizantes dos gêneros, priorizando a individualidade e as escolhas dos sujeitos. É uma forma de garantir a liberdade de gênero, compreender criticamente o tema e assegurar a inclusão dos sujeitos invisíveis. Nesse sentido, Guacira Lopes Louro (2000, p. 07)

\footnotetext{
Queer é tudo isso: é estranho, raro, esquisito. Queer é, também, o sujeito da sexualidade desviante - homossexuais, bissexuais, transexuais, travestis, drags. É o excêntrico que não deseja ser "integrado" e muito menos "tolerado". Queer é um jeito de pensar e de ser que não aspira ao centro como referência: é um jeito de pensar e de ser que desafia as normas regulatórias da sociedade, que assume o desconforto da ambiguidade, do "entre lugares", do indecidível. Queer é um corpo estranho, que incomoda, perturba, provoca e fascina.
}

A desconstrução dos padrões normativos da heterossexualidade vigente passa pelo entendimento de que a identidade de gênero não é predefinida aprioristicamente pelo modelo biológico. Além de se tratar de uma construção psicossocial que se dá ao longo da vida das pessoas, o "ser homem" e o "ser mulher" decorre de vivências, experiências, desejos, vontades e expectativas. Impor um modelo universalizante e uniforme de como as pessoas vivenciarão sua sexualidade, categorizando-as, é uma forma de violentá-las, estimulando a exclusão, marginalidade e invisibilidade.

Superar o binarismo é o meio de proteger integralmente as pessoas nas suas escolhas de gênero, sem estigmatizá-las. É resguardar a visibilidade, igualdade e inclusão.

\section{PROJETO DE LEI ESCOLA SEM PARTIDO $E$ SUA INCONSTITUCIONALIDADE POR VIOLAÇÃO DO DIREITO FUNDAMENTAL À LIBERDADE DE EXPRESSÃO DE GÊNERO E OFENSA À LIBERDADE DE CÁTEDRA}

Em 23 de março de 2015 o deputado federal Izalci, do PSDB do Distrito Federal, apresentou o Projeto de Lei número 867, cujo objetivo específico é incluir, dentre as diretrizes e bases da educação nacional o "Programa Escola sem Partido".

O respectivo projeto de lei foi apensado ao Projeto de Lei número 7180, de 2014, de autoria do deputado federal Erivelton Santana, do PSC da Bahia, cujo objetivo é alterar o artigo 3. da Lei 9.394/96 (Lei de Diretrizes e Base da Educação Nacional), para incluir entre os princípios do ensino o respeito às convicções do aluno, de seus pais ou responsáveis, dando 
precedência aos valores de ordem familiar sobre a educação escolar nos aspectos relacionados à educação moral, sexual e religiosa.

O artigo 2, do Projeto de Lei 867, estabelece que a educação nacional atenderá aos seguintes princípios: "I- neutralidade política, ideológica e religiosa do Estado; VII - direito dos pais a que seus filhos recebam a educação moral que esteja de acordo com suas próprias convicções" (BRASIL, Projeto de Lei 867).

No artigo 3. está previsto que "São vedadas, em sala de aula, a prática de doutrinação política e ideológica, bem como a veiculação de conteúdos ou a realização de atividades que possam estar em conflito com as convicções religiosas ou morais dos pais ou responsáveis pelos estudantes" (BRASIL, Projeto de Lei 867).

No artigo 4. o respectivo projeto deixa claro os deveres dos professores, quais sejam:

I - não se aproveitará da audiência cativa dos alunos, com o objetivo de cooptá-los para esta ou aquela corrente política, ideológica ou partidária; II não favorecerá nem prejudicará os alunos em razão de suas convicções políticas, ideológicas, morais ou religiosas, ou da falta delas; III - não fará propaganda político-partidária em sala de aula nem incitará seus alunos a participar de manifestações, atos públicos e passeatas; IV - ao tratar de questões políticas, socioculturais e econômicas, apresentará aos alunos, de forma justa, as principais versões, teorias, opiniões e perspectivas concorrentes a respeito; V - respeitará o direito dos pais a que seus filhos recebam a educação moral que esteja de acordo com suas próprias convicções; VI - não permitirá que os direitos assegurados nos itens anteriores sejam violados pela ação de terceiros, dentro da sala de aula (BRASIL, Projeto de Lei 867).

Na justificativa do Projeto de Lei 867 o seu autor deixa claro que se trata de uma iniciativa conjunta de estudantes e pais "preocupados com o grau de contaminação políticoideológica das escolas brasileiras, em todos os níveis: do ensino básico ao superior" (BRASIL, Projeto de Lei 867).

O deputado autor da proposta enaltece que professores e autores de livros didáticos vêm se utilizando de suas aulas e de suas obras para tentar obter a adesão de estudantes a determinadas correntes políticas e ideológicas, visando que os estudantes adotem padrões de julgamento e conduta moral (especialmente moral sexual) incompatível com os que lhes são ensinados por seus pais ou responsáveis. Deixa claro, dentre as justificativas, que o objetivo é prevenir a prática de doutrinação política e ideológica nas escolas, e a usurpação do direito dos pais a que seus filhos recebam a educação moral que esteja de acordo com suas próprias convicções. 
O conteúdo da presente proposta legislativa denota historicamente um resgate de ideologias autocráticas (fascistas e nazistas), de um setor da sociedade que ainda compreende a escola com um espaço privado de reprodução de valores familiares advindos da moral religiosa, contrariando o seu verdadeiro papel que é a formação do pensamento crítico dos alunos a partir de proposições teóricas, fundamentadas, debatidas e apresentadas pelo professor.

Pensar a escola com uma extensão dos valores familiares e religiosos é negar seu caráter coletivo e retirar sua função essencial, qual seja, o debate amplo de questões plurais que marcam significativamente a diversidade vigente na sociedade contemporânea. Além disso, é uma forma de excluir e marginalizar aqueles alunos que não se enquadram nos padrões de moralidade imposta por essas entidades familiares que ditam no espaço escolar seu modo de segregar e excluir todos aqueles que não se identificam com os seus valores. Trata-se de um meio de fomentar a exclusão, a marginalidade, a invisibilidade das "ditas" minorias, criando um ambiente de profunda segregação e hostilidade.

A escola delimita espaços; define os papéis sociais que serão assumidos por cada indivíduo ao longo da vida; inclui, ao mesmo tempo que exclui as pessoas. É na escola que aprendemos a solidariedade, construímos a socialidade, sociabilidade ${ }^{6}$, eticidade e aprendemos que as realidades de mundo vão muito além dos valores reproduzidos pela família.

O texto da Constituição brasileira de 1988 e a Lei de Diretrizes e Base da Educação Nacional propõe o estímulo do diálogo entre família e escola, de modo a deixar claro que a escola é um lócus de amplo debate livre e democrático das questões plurais que caracterizam a sociedade brasileira na atualidade.

Não é conferido à família o direito de retirar dos docentes a autonomia de cátedra e transformar a escola num espaço de reprodução de dogmas e ideologias que muitas vezes não contemplam a diversidade e pluralidade típica de qualquer ambiente escolar. A família não goza da legitimidade jurídica de limitar o direito de liberdade de expressão dos discentes em construir sua formação de acordo com suas convicções cientificas.

\footnotetext{
${ }^{6}$ Os processos educativos estão relacionados à socialização e é imprescindível a compreensão da análise de gênero na instituição escolar, visando a contribuição de comportamentos e práticas não-sexistas, aceitação da diversidade e tolerância ao outro. A partir desse pensamento a escola estará contribuindo para o questionamento dessa norma estabelecida, rompendo com uma história patriarcal que consolidou por muito tempo um currículo escolar androcêntrico e rascista. Não optar por essa alternativa, significa que a escola mantém a ordem dominante e naturaliza comportamentos de subordinação (OLIVEIRA, 2015, p. 267).
} 
Os respectivos projetos de lei (Projeto de Lei 867 e Projeto de Lei 7180) padecem de vício de constitucionalidade no momento em que contrariam o disposto no artigo 206 da Constituição brasileira de 1988, que é claro ao estabelecer que o ensino será ministrado com base nos princípios da liberdade de aprender, ensinar, pesquisar e divulgar o pensamento, a arte e o saber, além do pluralismo de ideias e concepções pedagógicas.

Considerando-se que a educação busca o pleno desenvolvimento das pessoas para o exercício da cidadania e sua qualificação profissional (artigo 205), verifica-se que tais projetos retiram dos indivíduos o direito de se tornarem cidadãos e serem respeitados no âmbito de suas escolhas.

Outro dispositivo constitucional violado é o inciso IX, do artigo 5. da Constituição brasileira de 1988, que é claro ao estabelecer que "é livre a expressão da atividade intelectual, artística, científica e da comunicação, independentemente da censura". Na contramão do que temos previsto no texto constitucional, o artigo 4. do Projeto de Lei 867 é categórico ao proibir o debate político e de questões de gênero no âmbito escolar, sugerindo no parágrafo único do artigo 7 a possibilidade de criminalização de condutas praticadas pelos professores que violarem as proibições referentes ao debate político-partidário e de gênero no âmbito escolar.

Considerando-se que a política é um debate de cunho cientifico e que a formação política dos indivíduos é essencial para o exercício da cidadania, ressaltando-se que o professor é quem detém a legitimidade jurídica para construir e fomentar debates políticos e de gênero no âmbito escolar, evidencia-se que tal proposta legislativa além de claramente inconstitucional denota o intuito de institucionalizar a censura no Brasil.

Um terceiro fundamento para justificar a inconstitucionalidade das propostas legislativas supramencionadas encontra-se no artigo 1. da Constituição brasileira de 1988, que é categórico ao prever que a República Federativa do Brasil constitui-se em Estado Democrático de Direito e tem como fundamentos o pluralismo político e a cidadania.

A escola é o espaço destinado a promover a formação política dos indivíduos, permitindo-se conhecer teorias e proposições que explicam histórica e sociologicamente as entrelinhas dos acontecimentos atuais. É a oportunidade que o cidadão tem de ler e compreender as entrelinhas da história, superando as concepções meramente dogmáticas e ideológicas. 
A educação vista como um direito fundamental subjetivo deve ser interpretada no Estado Democrático de Direito de forma extensiva e sistemática, permitindo-se aos docentes e discentes ampla liberdade de pensamento cientifico, para que possam construir e desconstruir teorias, concepções de mundo e revisitar vivências a partir da racionalidade crítica.

Um quarto fundamento jurídico hábil a demonstrar a inconstitucionalidade dos projetos de lei em tela encontra-se no artigo 3., inciso IV da Constituição de 1988, que prevê que constitui objetivo fundamental da República Federativa do Brasil promover o bem de todos, sem preconceitos de origem, raça, sexo, cor, idade e quaisquer outras formas de discriminação. No momento em que se pretende tornar a escola num espaço privado em que a família reproduz seus valores morais e religiosos, ficará evidente a segregação racial, discriminação de gênero, além do estímulo ao bullying sofrido por aqueles alunos que não se enquadrarão no modelo de família tradicional e cristã preconizado pelas proposições legislativas apresentadas.

A liberdade de expressão ${ }^{7}$ e de manifestação cientifica é considerada um dos fundamentos regentes do Estado Democrático de Direito. Garantir a igualdade jurídica de debate a todos os interessados (docentes e discentes) no âmbito escolar é uma forma de construir discursivamente proposições teóricas, críticas e refutáveis.

A escola deve promover debates transdisciplinares, que atendam aos anseios e as necessidades de uma sociedade globalizada marcada pelo pluralismo. O projeto de lei intitulado "Escola Sem Partido" contraria o texto da constituição democrática no momento em que censura o professor, afronta sua liberdade de cátedra e limita o espaço discursivo da sala de aula, proibindo debates políticos e de gênero, comprometendo a formação multifacetária dos indivíduos para o exercício da cidadania, estimulando o preconceito e a exclusão.

A liberdade sexual é um direito fundamental corolário da dignidade humana. A igualdade jurídica de tratamento dado às pessoas em razão de suas manifestações de gênero é uma forma de retirar-lhes sua invisibilidade, inclui-las no debate democrática, descosificá-las. Nesse sentido

a liberdade sexual, entendida como aquela parte da liberdade referida ao exercício da própria sexualidade e, de certo modo, a disposição do próprio corpo, aparece como bem jurídico merecedor de uma proteção específica,

\footnotetext{
7 "o regime democrático é uma garantia geral da realização dos direitos humanos fundamentais. Vale dizer, portanto, que é na democracia que a liberdade encontra campo de expansão. É nela que o homem dispõe da mais ampla possibilidade de coordenar os meios necessários à realização de sua felicidade pessoal. Quanto mais o processo de democratização avança, mais o homem se vai libertando dos obstáculos que o constrangem, mais liberdade conquista" (SILVA, 2011, p. 234).
} 
não sendo suficiente para abranger toda sua dimensão a proteção genérica concedida à liberdade geral (CONDE, 2004, p. 206).

"Resumidamente pode-se afirmar que a liberdade de ensinar aparece no texto constitucional como liberdade institucional e como liberdade docente. Em ambos os casos ela é limitada por um conjunto de outros princípios e garantias constitucionais e pela estrutura do sistema educacional brasileiro" (RODRIGUES; MAROCCO, 2014, p. 6-7).

A liberdade de ensinar, compreendida como liberdade de cátedra, consiste na legitimidade conferida ao docente de conduzir o processo ensino-aprendizagem na perspectiva crítico-epistemológica, não podendo sofrer qualquer ingerência estatal no sentido de retirar-lhe o direito de expor e debater cientificamente no espaço da sala de aula.

Ao Estado cabe o direito de estabelecer parâmetros gerais de conteúdos que integrarão a matriz curricular de cada ciclo escolar, ressaltando-se que o docente não pode ignorar tais parâmetros e conduzir a formação de seus alunos do modo que bem entender.

$\mathrm{O}$ ato de ensinar materializa-se no direito de aprender, ou seja, tanto docente quanto discente ensinam e aprendem no âmbito escolar. O docente pode se utilizar de metodologias, estratégias e concepções pedagógicas para trabalhar em sala de aulas análises plurais e transdisciplinares de temas que integram os parâmetros curriculares.

A imposição de dogmas e concepções unilaterais de mundo fere a democraticidade do ensino, pois a construção do espaço discursivo em sala de aula deve garantir ao docente e aos discentes a igualdade jurídica de oportunidade na construção do conhecimento científico.

O professor não pode se limitar a impor visões subjetivas e unilaterais na forma de compreender os fenômenos jurídicos. O respeito ao saber do educando ${ }^{8}$, a consciência do inacabamento ${ }^{9}$, a convicção de que a mudança é possível $^{10}$ e o entendimento de que a

\footnotetext{
${ }^{8}$ Por que não discutir com os alunos a realidade concreta a que se deva associar a disciplina cujo conteúdo se ensina, a realidade agressiva em que a violência é a constante e a convivência das pessoas é muito maior com a morte do que com a vida? Por que não estabelecer uma "intimidade" entre os saberes curriculares fundamentais aos alunos e a experiência social que eles têm como indivíduos? Por que não discutir as implicações políticas e ideológicas de um tal descaso dos dominantes pelas áreas pobres da cidade? A ética da classe embutida neste descaso? Porque, dirá um educador reacionariamente pragmático, a escola não tem nada a ver com isso. A escola não é partido. Ela tem que ensinar conteúdos, transferi-los aos alunos. Aprendidos, estes operam por si mesmo (FREIRE, 2011, p. 32).

${ }^{9} \mathrm{Na}$ verdade, o inacabamento do ser ou sua inconclusão é próprio da experiência vital. Onde há vida, há inacabamento. Mas só entre mulheres e homens o inacabamento se tornou consciente (FREIRE, 2011, p. 50).

${ }^{10}$ Ninguém pode estar no mundo, com o mundo e com os outros de forma neutra. Não posso estar no mundo de luvas nas mãos constatando apenas. A acomodação em mim é apenas caminho para a inserção, que implica decisão, escolha, intervenção na realidade. Há perguntas a serem feitas insistentemente por todos nós e que nos fazem ver a impossibilidade de estudar por estudar. De estudar descomprometidamente como se
} 
educação é uma forma de intervenção no mundo ${ }^{11}$ são meios hábeis ao entendimento de que a liberdade de cátedra, quando exercida com legitimidade, assegura ao discente uma formação transdisciplinar e epistemológica.

Impedir, limitar ou obstaculizar o debate das questões de gênero no ambiente escolar, além de legitimar exclusão e invisibilidade daqueles sujeitos que não se enquadram nos padrões unilateralmente impostos pela moral social, torna a instituição um espaço de reprodução de violência, opressão e desigualdade.

\section{CONCLUSÃO}

O direito fundamental à educação deve ser interpretado sistematicamente de forma extensiva, oportunizando a todos, indistintamente, o direito de frequentar a escola e nela buscar uma formação crítica que legitima o exercício da cidadania no Estado Democrático de Direito.

A escola é o espaço de debate científico, político, transdisciplinar e sistemático de temas de interesse da sociedade contemporânea, marcada pelo pluralismo e diversidade. É nela que as pessoas desenvolvem a socialidade, sociabilidade e constroem a eticidade como meios de enxergar o outro de forma igual, respeitando-o em suas diferenças.

Na sala de aula é onde deve ocorrer estudos científicos voltados ao entendimento das questões de gênero, desconstruindo o binarismo, revisitando a patologização dos "diferentes", ressignificando dogmas da heterossexualidade imposta por valores morais que segregam e excluem as pessoas.

A discussão crítica das questões de gênero no âmbito escolar é tema relevante para a sociedade brasileira atual, marcada pela heterogeneidade na forma das pessoas expressarem de diversos modos sua sexualidade.

O gênero é uma construção psicossocial, reflexo da subjetividade e escolha dos indivíduos de se construírem e desconstruírem sexualmente ao longo da vida a partir de seus desejos. É uma forma de se expressar distinta da concepção biológico-evolucionista que

misteriosamente, de repente, nada tivéssemos que ver com o mundo, um lá fora e distante mundo, alheado de nós e nós dele (FREIRE, 2011, p. 75).

${ }^{11}$ Como experiência especificamente humana, a educação é uma forma de intervenção no mundo. Intervenção que, além do conhecimento dos conteúdos bem ou mal ensinados e/ou aprendidos, implica tanto o esforço de reprodução da ideologia dominante quanto o seu desmascaramento. Dialética e contraditória, não poderia ser a educação só uma ou só a outra dessas coisas. Nem apenas reprodutora nem apenas desmascaradora da ideologia dominante (FREIRE, 2011, p. 96). 
classifica as pessoas em "machos" e "fêmeas". O "ser mulher" e o "ser homem" são manifestações que não devem ser categorizadas, tampouco patologizadas quando destoa da moralidade vigente.

O projeto de lei denominado "Escola Sem Partido" propõe a neutralidade cientifica do docente, censurando-o no que atine ao debate de questões políticas e de gênero no ambiente escolar. Trata-se de proposição que visa tornar a escola um espaço privado de prevalência dos valores familiares decorrentes da moral-religiosa que segrega, exclui, marginaliza e reproduz a violência física, psíquica e moral das pessoas que não se enquadram no modelo heterossexual vigorante.

O respectivo projeto de lei é considerado inconstitucional por ofender o Estado Democrático de Direito, obstaculizar o exercício da cidadania, além de atentar contra a liberdade de cátedra, direito fundamental expressamente previsto no texto constitucional. A violação do direito fundamental à liberdade de expressão de gênero, corolário da liberdade sexual, também é outro argumento jurídico utilizado para demonstrar a incompatibilidade de tal proposição legislativa com o atual ordenamento jurídico-constitucional brasileiro.

Proibir o debate das questões de gênero no ambiente escolar é manter a doutrina da exclusão, reproduzir o machismo, estimular a violência, perpetuar a coisificação da mulher, excluir os travestis, transexuais e demais pessoas que fogem ao padrão moral de sexualidade imposta por dogmas religiosos.

Um dos objetivos fundamentais da República Federativa do Brasil é a vedação de qualquer discriminação referente à origem, raça, sexo, cor e idade, expressamente previsto no artigo 3. da Constituição brasileira de 1988. Sua efetivação passa diretamente pela compreensão científico-racional dos gêneros, ressaltando-se que a escola é o local onde tais estudos serão desenvolvidos. Para isso, tanto docentes quanto discentes precisam compreender que a educação é um direito subjetivo, de natureza pública e, por isso, a escola não pode ser vista como uma extensão privada dos valores familiares cristãos.

\section{REFERÊNCIAS}

ARAÚJO. Luiz Alberto David; NUNES JÚNIOR, Vidal Serrano. Curso de Direito Constitucional. 8. ed. revista e atualizada. São Paulo: Saraiva, 2004.

ARENDT, Hannah. A Condição Humana. Rio de Janeiro: Forense Universitária, 2007. 
BOURDIEU, Pierre. A dominação masculina. Tradução Maria Helena Kühner. 5. ed. Rio de Janeiro: Bertrand Brasil, 2007.

BUTLER, Judith. PROBLEMAS DE GENNERO: feminismo e subversão da identidade. Rio de Janeiro: Civilização Brasileira, 2003.

BRASIL. Supremo Tribunal Federal. Disponível em http://redir.stf.jus.br/paginadorpub/paginador.jsp?docTP=AC\&docID=257829. Acesso em 25 jul. 2017.

BRASIL. Projeto de Lei 867, de 2015. Disponível em http://www.camara.gov.br/sileg/integras/1317168.pdf. Acesso em 16 jun. 2017.

CONDE, Francisco Munoz. Derecho Penal: parte especial. 15.ed. Valencia: Editora Tirant Lo Blanch, 2004.

DUARTE, Clarice Seixas. DIREITO PÚBLICO SUBJETIVO E POLÍTICAS EDUCACIONAIS. SÃO PAULO EM PERSPECTIVA, 18(2): 113-118, 2004. Disponível em http://www.scielo.br/pdf/spp/v18n2/a12v18n2.pdf. Acesso em 26 jul. 2017.

FREIRE, Paulo. PEDAGOGIA DA AUTONOMIA - Saberes Necessários à Prática Educativa. São Paulo: Paz e Terra, 2011.

JARDIM, R. T.; TUSSI. Trabalhando Gênero e os Direitos das mulheres em sala de aula. In: MEIRELLES. M. et al.(Org.) Ensino de Sociologia: Diversidade, Minorias, Intolerância e Discriminação social. UFRGS.2013.

LOPES, Laís. O QUE É GÊNERO? GÊNERO, SEXUALIDADE E DIREITO- uma introdução. Organização Marcelo Maciel Ramos, Paula Rocha Gouvêa Brener e Pedro Augusto Gravatá Nicoli. Belo Horizonte: Initia Via, 2016.

LOURO, Guacira Lopes (org).O corpo educado - pedagogia da sexualidade. Belo Horizonte: Autêntica, 2000.

LOURO, Guacira Lopes. Gênero, sexualidade e educação. Uma perspectiva pósestruturalista. Petrópolis: Vozes, 2014.

MONTEIRO, Raquel Motta Calegari. A EDUCAÇÃO NO BRASIL: direito social e bem público.

Disponível

em https://www.uniso.br/publicacoes/anais_eletronicos/2014/3_es_mercado_e_sociedade/04.pdf. Acesso em 07 jul. 2017.

OLIVEIRA, Danilo Araújo de. O espaço escolar numa perspectiva de gênero. Educação $e$ Igualdade de Gênero. Organizadores Alfrancio Ferreira Dias e Maria Helena Santana Cruz. Jundiaí: Paco Editorial, 2015.

PORCHAT, Patrícia. PSICANÁLISE E TRANSEXUALISMO - Desconstruindo Gêneros e Patologias com Judith Butler. Curitiba: Juruá, 2014.

RODRIGUES, Horácio Wanderlei; MAROCCO, Andréa de Almeida Leite. Liberdade de cátedra e a Constituição Federal de 1988: alcance e limites da autonomia docentes. In: 
CAÚLA, Bleine Queiroz et al. Diálogo ambiental, constitucional e internacional. Fortaleza: Premius, 2014. v. 2. p. 213-238.

SAVELI, Esméria de Lourdes; TENREIRO, Maria Odete Vieira. A EDUCAÇÃO ENQUANTO DIREITO SOCIAL: aspectos históricos e constitucionais. Disponível em http://www.dtp.uem.br/rtpe/volumes/v15n2/04.pdf. Acesso em 03 jul. 2017.

SEVERO, Rafael Adriano de Oliveira. GÊNERO E SEXUALIDADE NO COTIDIANO DA ESCOLA: a morte social causada pelo bullying homofóbico. Outros Plurais - mulheres e homens na educação. Organizadores Adla Betsaida Martins Teixeira e Marcel de Almeida Freitas. Curitiba: CRV, 2013.

SEVERO, Rafael Adriano de Oliveira. GÊNERO E SEXUALIDADE - Grupos de Discussão como Possibilidade Formativa. Jundiaí: Paco Editorial, 2013.

SILVA, Fábio de Sousa Nunes da. Análise crítica quanto efetivação do direito fundamental à educação no Brasil como instrumento de transformação social. Disponível em http://www.lfg.com.br Acesso em 10 jul. 2017.

SILVA, José Afonso da. Curso de Direito Constitucional Positivo. 34.ed. São Paulo: Malheiros, 2011.

SOUZA, Lívia de. O QUE É VIOLÊNCIA DE GÊNERO? GÊNERO, SEXUALIDADE E DIREITO- uma introdução. Organização Marcelo Maciel Ramos, Paula Rocha Gouvêa Brener e Pedro Augusto Gravatá Nicoli. Belo Horizonte: Initia Via, 2016.

TAQUETTE, Stella R. HOMOSSEXUALIDADE E ADOLESCÊNCIA sob a ótica da saúde. Rio de Janeiro: EdUERJ, 2015. 